\title{
LOS NOMBRAMIENTOS INTERINOS DE DOCENTES EN LA JURISPRUDENCIA CONSTITUCIONAL ${ }^{1}$
}

\author{
Jimmy Bolaños González ${ }^{2}$
}

\begin{abstract}
Resumen: La situación laboral en el sector puiblico educativo, en relación con los miles de servidores que imparten lecciones en los centros educativos del Ministerio de Educación Püblica es ampliamente tratada a la luz de una amplia sistematización y cita de las resoluciones de la Sala Constitucional emitidas por cientos en los ültimos años. Se analiza el marco juidico general que regula la posibilidad de sustituir a un interino versus el derecho fundamental al trabajo y a la estabilidad garantizadas por los numerales 56 y 192 de la Carta Magna respectivamente. Se procura contemplar la amplia casuistica que puede existir, con el fin de contribuir a la certeza y seguridad juridica que ba de imperar en todo el ordenamiento juridico, de modo que pueda salirse al paso de arbitrariedades y abusos, no solo de las autoridades de la cartera ministerial como patrono sino incluso de los mismos docentes que acuden a la via de amparo en algunos casos en forma "temeraria" tan solo para alargar sus nombramientos mientras el Tribunal Constitucional resuelve su caso.
\end{abstract}

\section{Introducción}

En el marco más amplio de los derechos de los servidores nombrados interinamente al servicio de la Administración Públi$\mathrm{Ca}^{3}$, pretendemos profundizar el dato jurisprudencial emanado del Tribunal Constitucional, en lo que atañe a la relativa estabilidad que se le han otorgado en la última década a los servidores interinos, analizando en particular el caso de los propiamente docentes del Ministerio de Educación Pública.

Esta actuación jurisdiccional vino a modificar sustancialmente lo que se consideraba el ejercicio de una amplia e ilimitada facultad discrecional de la Administración para "quitar y poner a los libremente interinos", por considerarlo tanto violatorio de los derechos del servidor como perjudicial para la finalidad estatutaria de eficiencia de la propia Administración Pública.

La jurisprudencia es copiosísima, en el tanto en esa cartera ministerial existen miles de plazas vacantes en las que en cada curso lectivo son designadas personas cuyos nombramientos son provisionales, sea por licencia o incapacidad del titular quien entonces ha de ser sustituido ${ }^{4}$, con el fin de que los niños y jóvenes que asisten a los centros educativos no se queden, ojalá, ni un solo día sin lecciones.

También se tienen casos comunes de puestos vacantes -de vieja data, así como por 
renuncia reciente y otros que año a año se crean para atender las crecientes necesidades del servicio educativo en éste último caso mientras se concluyen los procedimientos de admisión de un servídor en propiedad, en los que se hacen nombramientos interinos (en condición de suplencia o no), que se justifican en la necesidad de no interrumpir el servicio público educativo a fin de que continúe funcionando.

En todo caso, al inicio de cada curso lectivo, suelen acudir a la Sala Constitucional, en la vía de amparo, muchos educadores que prestaron servicios interinamente durante el curso lectivo anterior y consideran violentados sus derechos al no obtener en el siguiente curso lectivo el nombramiento que esperaban, situación sobre la cual quisiéramos con este artículo arrojar luz, en beneficio tanto del sistema de méritos como del proceso educativo, y por ende del país en general.

\section{El derecho del servidor interino a una estabilidad "impropia"}

En la última década, han sido las resoluciones de la Sala Constitucional las que han venido agregando nuevos derechos ${ }^{5}$ en favor de los servidores interinos, brindando el marco general que debe seguir la Administración en estos casos, dado el carácter vinculante "erga omnes" de la jurisprudencia y los precedentes de la jurisdicción constitucional (cfr. Artículo 13 de la Ley de la Jurisdicción Constitucional).

Es así como a partir de la Resolución No. 743-91 de las 15:35 horas del 17 de abril de 1991 y con abundantísima jurisprudencia posterior, sustentándolo tanto en el derecho al trabajo ${ }^{6}$ que consagra el numeral 56 de la Constitución Política, como en una discriminación irracional en perjuicio de su "estabilidad"7, nuestro Tribunal Constitucional ha sostenido reiterada y constantemente la improcedencia de sustituir a un interino por otro en las mismas condiciones de nombramiento, ya que ello violentaría los derechos del empleado cesado, de manera que les ha concedido si no una estabilidad propia como la que poseen los funcionarios en propiedad, sí una estabilidad que ha denominado "impropia" para los empleados interinos, según la cual dichos servidores tienen derecho a permanecer ocupando esas plazas hasta tanto no exista una necesidad objetiva de servicio público, que como consecuencia de la misma, haga desaparecer la causa que dio origen al nombramiento y ameritar prescindir de la contratación en tales condiciones de interinidad.

Puede verse, por ejemplo, que Sala Constitucional en Resolución No. 1755-91 de las 15:02 horas del 5 de setiembre de $1991^{8}$ ha dicho que:

"...es indispensable indicar que para que un asunto de naturaleza laboral sea de revisión por parte de esta Sala, se requiere que el funcionario público esté sujeto a lo que la doctrina Constitucional ha dado en llamar estabilidad propia, es decir que se encuentre adscrito al Régimen del Servicio Civil y por ende, que tenga garantizada su estabilidad laboral. La estabilidad impropia, -que es la que tiene la accionante por su condición interina- se caracteriza porque el patrono puede prescindir de este personal, aún sin procedimiento previo, siempre que actúe dentro de las situaciones objetivas de necesidad de servicio. En forma reiterada esta Sala ha señalado que el error no crea derecho y que las simples comunicaciones telegráficas no tienen la virtud de consolidar un nombramiento, sino que este nace a la vida jurídica cuando se cumple con el procedimiento que al efecto establecen las normas legales y reglamentarias aplicables...".

\section{La terminación del nombramiento de un interino en el Título I}

En el ámbito del Título Primero del Estatuto de Servicio Civil, que aplica para todos los servidores administrativos amparados al régimen de méritos en el ámbito del Poder Ejecutivo, los cambios operados a raíz de la jurisprudencia constitucional en el tema que nos ocupa, fueron analizados ampliamente en sus alcances por la Asesoría Jurídica de la Dirección General de Servicio Civil en su dictamen AJ-168-94 del 19 de mayo de 1994. 
La posición que dichos pronunciamientos legales sostienen es conteste con los alcances de los fallos del Tribunal Constitucional, de modo que en virtud de la estabilidad impropia del servidor interino, se indica que no es factible sustituirlo hasta tanto no lo sea por un servidor propietario, que accediera a esa condición mediante los mecanismos concursales $^{9}$ y escogimiento de terna ${ }^{10}$ respectivos, así como en otros supuestos tales como: la comisión de una falta grave de servicio, previo debido proceso legal y derecho de defensa respectivo ${ }^{11}$; el regreso del titular ${ }^{12}$, llenar la plaza por promoción o traslado en propiedad ${ }^{13}$ no interinamente ${ }^{14}$, dejar el servidor interino de llenar los requisitos o perfil del cargo $^{15}$ por modificaciones al mismo, no prorrogar el nombramiento interino porque se considera innecesario el uso del puesto o por políticas de ahorro en el gasto público $^{16}$, etc.

Se trata de supuestos razonables y proporcionados que en realidad son de aplicación en todo el ámbito del empleo en la Administración Pública en sentido amplio, de los cuales no escapan el colectivo docente: cuando el interino es cesado por comisión de una falta previo procedimiento disciplinario ${ }^{17}$, cuando se cesa el interino por regreso del titular ${ }^{18}$; nombramiento por escogimiento de terna $^{19}$, traslado $^{20}$ o ascenso ${ }^{21}$ en propiedad - no interinamente ${ }^{22}$ - de un servidor o porque terminado el nombramiento no se prorrogó el mismo ni se designó a nadie más ${ }^{23}$.

No obstante, en el caso de los servidores docentes aumenta la enumeración, en virtud de algunos supuestos particulares del servicio público educativo como por ejemplo: la disminución de matrícula ${ }^{24}$, el recargo interi$n^{25}$, el que no se haya autorizado el código de pago para la sustitución de ese puesto ${ }^{26}$, aunque no se admite el cese de interinato por motivos de cambio de funciones en razón de enfermedad laboral ${ }^{27}$ dispuesto por el Instituto Nacional de Seguros, y en aplicación del Reglamento de Licencias Especiales ${ }^{28}$.

Cabe señalar que la regla general de no sustituir al interino por otro se aplica aún en el caso de los nombramientos de personal docente que el Ministerio de Educación Pública subvenciona con el pago de su planilla para que laboren en determinados centros educativos privados 29 .

Sin embargo, veremos a continuación que las particularidades del régimen de carrera docente, han dado lugar a novedosas situaciones administrativas adicionales, en las cuales el Tribunal Constitucional ha aceptado que la Administración está legalmente facultada para sustituir un interino por otro e incluso simplemente no nombrarlo en el siguiente curso lectivo.

\section{La terminación del nombramiento de un interino en el Título $\mathrm{II}^{30}$}

El Título Segundo del Estatuto de Servicio Civil, conocido también como Ley de Carrera Docente (Ley No. 4565 de 4 de mayo de 1970 y sus reformas), regula al multitudinario colectivo funcionarial de los docentes que prestan servicio al Ministerio de Educación Pública, conteniendo disposiciones propias y específicas, en atención a las características tanto del docente como tal -en su preparación académica y demás atestados- y la naturaleza tanto del proceso como del servicio educativo en particular.

Así, el ordinal 107 de esa ley clasifica al personal en tres segmentos: profesores titula$\operatorname{dos}^{31}$, profesores autorizados ${ }^{32}$ y profesores aspirantes ${ }^{33}$, de acuerdo con su nivel de preparación, además de que para cada uno de esos segmentos se regula un escalafón diferenciado en grupos profesionales, conforme también a los atestados de cada quien (véanse los numerales 114 y siguientes de la ley, porque además se distribuyen las denominaciones de esos grupos profesionales por el nivel -ejemplo: preescolar (KT-KAO), primaria (PT), secundaria- y modalidad de enseñanza -ejemplo: para ejercer la docencia en centros académicos (MT-MAU) o técnicos-profesionales (VT-VAU), enseñanza especial (ET, EAU), etc. 
Como regla general, los nombramientos de servidores docentes deben responder como mínimo a dos prioridades para efectos de seleccionar al más idóneo: el segmento al que pertenecen (titulados, autorizados y aspirantes, de modo que debe preferirse a los primeros sobre los segundos, y a los segundos sobre los terceros); en segundo lugar, si los candidatos pertenecen a un mismo segmento, se ha de escoger al mayor grupo profesional en que se ubique según sus requisitos en el respectivo segmento, con lo cual se aseguran mejor los fines de la Ley de Carrera Docente (Artículo 53 de la ley), el respecto al sistema de méritos y en definitiva contar en las aulas con los docentes más idóneos posibles, redundando en bien de toda la educación y del desarrollo nacional.

No obstante, debe considerarse que no todo el personal calificado y con mayor grupo profesional está uniformemente distribuido a lo largo y ancho del territorio nacional, en el cual se ubican todos los miles de centros educativos, como tampoco necesariamente ciertos centros educativos son atractivos por muy diversos motivos para que maestros y profesores estén dispuestos a ejercer la docencia en ellos, lo que provoca que en la práctica no existan ofertas de personal calificado o la misma es insuficiente, trayendo consigo la necesidad de las autoridades ministeriales de nombrar algún maestro o profesor con ninguna o baja calificación profesional, para cumplir con la obligación del Estado de garantizar el derecho fundamental a la educación y no perjudicar a los alumnos que esperan recibir sus clases en el respectivo curso lectivo.

Estos últimos casos dan lugar a inopia, y se encuentran debidamente regulados por la ley en los siguientes términos:

"Artículo 96.-Cuando una plaza del personal propiamente docente a que se refiere el artículo 83 , quedare libre por concepto de licencia, permiso del titular o cualquier otro motivo, durante un periodo mayor de un año y hubiere de ser llenada con un servidor interino, éste deberá ser nombrado siguiendo el orden descendente de la nómina de elegibles, siempre que el candidato no tuviera plaza en propiedad de la misma clase de puesto.
Cuando una plaza del personal propiamente docente quedare libre durante el curso lectivo o parte de éste, por motivo de licencia, permiso del titular o cualquier otra razón, el Ministerio de Educación Pública nombrará, en forma interina, al profesor sustituto que a su juicio sea más idóneo, del personal calificado del Registro que debe mantener la Dirección General de Servicio Civil. En ninguna circunstancia podrá nombrarse personal no calificado, salvo en los casos de inopia, de acuerdo con las normas del artículo 97 siguiente.

En todo caso, la aceptación de un nombramiento interino por parte de un servidor calificado, por todo el período o el resto del curso lectivo, impedirá que durante dicho periodo sea escogido de la nómina de elegibles para un puesto en propiedad. La condición de interinidad impedirá el nombramiento en propiedad de un servidor calificado que haya sido nombrado por el resto del curso lectivo. Si durante el período lectivo se produjeren vacantes, éstas podrán ser llenadas por servidores interinos, hasta el final del curso, o hasta el último día de febrero del siguiente año, según la naturaleza y condiciones del puesto. Los interinos que por su puntuación hubieren sido nombrados en plazas vacantes o en otras cuyos titulares gozaren de licencia o permiso, podrán continuar desempeñándolas, mientras no hayan podido ser llenadas o se prorrogare la licencia o permiso de éstos".

(Reformado por ley No. 4889 de 17 de noviembre de 1971).

"Artículo 97.-A falta de personal calificado para servir plazas en instituciones educativas de cualquier tipo, podrán ser designados para ocuparlas, candidatos que, sin reunir la totalidad de los requisitos, se hayan sometido a pruebas de aptitud o concurso de antecedentes, que permitan seleccionar el candidato de mayor idoneidad, a juicio del Departamento de Personal del Ministerio de Educación Pública, quien contará para ello, con los servicios de los asesores supervisores correspondientes.

Estos servidores ocuparán los cargos en calidad de "autorizados" o "aspirantes" y permanecerân en sus puestos mientras no haya personal calificado. Quedan a salvo los casos previstos en el artículo siguiente.

Las relaciones de los educadores que ocupen puestos "interinos", se regirán por las disposiciones reglamentarias pertinentes, sobre contratos o (sic) plazo fijo".

Con fundamento en lo anteriormente expuesto, se tiene entonces que en el caso concreto de sustituir a un servidor interino docente por otro interino, se conserva la regla general de que ello es improcedente por arbitrario, de forma tal que debe la Administración prorrogar el nombramiento para el siguiente curso lectivo, caso contrario el afectado puede, por la vía de amparo, hacer valer su derecho a la estabilidad impropia (Véanse 
las resoluciones Nos. 1141-96 de las 15:21 horas del 06 de marzo de 1996, 1682-96 de las 10:36 horas del 12 de abril de 1996 y $2124-96$ de las 15:09 horas del 8 de mayo de 1996, entre otros muchos).

No obstante, en determinados casos sí sea procedente sustituir a un servidor interino por otro, aún cuando lo sea en igual condición de provisionalidad o temporalidad, lo cual aplica en los casos en los que para el siguiente curso lectivo se logra contratar a un docente calificado que sustituya al aspirante ${ }^{34}$ o autoriza$\mathrm{do}^{35}$ que se tuvo que nombrar por inopia ${ }^{36}$.

Lo anterior puede implicar no sólo la posibilidad fáctica y jurídica de sustituir a un interino aspirante o autorizado por un interino calificado sino incluso a un aspirante por un calificado ${ }^{37}$.

Tal actuación administrativa no sólo significa cumplir a cabalidad con la ley de carrera docente, sus fines y regulaciones, sino que se sustenta en que esa mayor idoneidad del personal docente redunda en beneficio de la excelencia del sistema educativo, todo lo cual, más o menos en esos términos, ha sido reiteradamente sostenido con justa razón por la Sala Constitucional en su jurisprudencia ${ }^{38}$.

Incluso, aún los nombramientos de interinos realizados en lugares alejados $e$ insalubles al amparo de lo regulado por el numeral 98 del Estatuto de Servicio Civil, no autorizan para no considerar a un docente calificado dispuesto a servir en esas localidades, puesto que el estar estudiando al amparo de convenios, brinda una prioridad en la designación a los que estén en igualdad de condiciones, pero no frente a profesionales que ya han adquirido una categoría mayor ${ }^{39}$.

Si el panorama es claro y pacífico en punto a la procedencia jurídica de sustituir a un docente interino aspirante o autorizado por un docente también en condición interino pero titulado -es decir, calificado-, no sucede igual al considerar la situación de los servidores interinos cuando son titulados -tanto el sustituido como el sustituto- pero calificados en distinto grupo del escalafón profesional.
El pretender la Administración sustituir a un interino por otro en igual condición de nombramiento, en donde ambos son calificados, pero uno con mayor grupo que el otro, no ha sido aceptado por la Sala Constitucional ${ }^{40}$ :

\begin{abstract}
“...pues el criterio aplicado a base de méritos debió realizarse desde el inicio de la sustitución y no cuando esta ya se dio. Acoger el criterio de la accionada daría como resultado el hecho de que en el futuro, en detrimento de la estabilidad que cobija a los servidores interinos, se aduzca una mayor categoría profesional y prestarse ello para una mala aplicación del sistema de nombramientos del sector "público" (Resolución No. 1141-96 de las 15:21 horas del de marzo de 1996).
\end{abstract}

En otra resolución vuelve sobre este punto en los siguientes términos:

"Si bien es cierto el Régimen de la Carrera Docente es un régimen de méritos, según el cual ante una vacante o sustitución del titular en un puesto propiamente docente la Administración está obligada a llenar la plaza, aún interinamente, con el oferente mejor calificado, ello no puede entenderse en perjuicio de quien, como en este caso, ha venido siendo nombrado interinamente en el puesto y por ese misma razón goza de una estabilidad impropia que le otorga un derecho al puesto oponible a cualquier otro servidor interino, pero ciertamente no frente al titular. En efecto, esta Sala no desconoce que la Administración debe cumplir con las regulaciones y procedimientos establecidos en el Estatuto de Servicio Civil y su Reglamento, pero tales normas deben ser interpretadas correctamente a fin de que no se vulneren los derechos fundamentales de los servidores. Ahora bien, con excepción de los casos de inopia, en los cuales el nombramiento del servidor queda sujeto a la existencia de oferentes calificados para el cargo, la Aćministración no puede sustituir a un servidor interino por otro interino, aún cuando éste último esté mejor calificado, ya que la Administración está obligada a comprobar la idoneidad del servidor al momento de hacer su conbramiento. De manera que, si el Ministerio de Educación Pública había nombrado, en años anteriores, al aquí recurrente interinamente como Profesor de Educación Musical en la Escuela Los Guido de Desamparados por estar vacante la plaza, fue por cuanto el amparado cumplía con los requisitos para el cargo, pues no consta que lo fuera por inopia demostrada, de manera que era en ese momento en que la Administración debía nombrar a la persona más idónea según la lista de oferentes existente en ese momento, pero una vez verificado el nombramiento y comprobado el cumplimiento de los requisitos para el cargo, el servidor adquiere un derecho frente a cualquier otro servidor interino que se pretenda designar en el puesto que ocupa. La comprobación de idoneidad debe realizarla, entonces, la Administración en el momento de hacer el nombramiento interino inicial, sea en plaza vacante o en sustitución del titular, pues con ello surge un 
derecho a favor del servidor interino, sin que pueda verse afectado por la eventualidad de que, con posterioridad, aparezca otro oferente con mejor calificación. De manera que la interpretación que la Administración hace del numeral 114 del Estatuto de Servicio Civil, según el cual al momento de hacer el nombramiento se deberá tomar en cuenta a los candidatos de conformidad con el orden de grupos que establece el Estatuto, no es del todo correcta, pues ello es aplicable al momento de llenar interinamente la vacante o de hacef la sustitución del titular, pero no para efectos de la prórroga del nombramiento interino. Así las cosas, y toda vez que del informe rendido por el $\mathrm{Di}^{-}$ rector General de Administración de Personal del Ministerio de Educación Pública, se desprende que, no obstante haber venido ocupando el recurrente en forma interina una plaza como Profesor de Música en la Escuela Los Guido de Desamparados fue sustituido por otra funcionaria interina, se ha producido la acusada lesión a su derecho al trabajo y a la estabilidad en el puesto, pues aún cuando la servidora designada en su lugar tenga mejor calificación, el gestionante sí cumplía, al menos, con los requisitos para ocupar el puesto, -de lo contrario no se le prorrogaría por parte de la Administración, los nombramientos hasta ahora obtenidos por el recurrente- así como tampoco consta que hubiese sido nombrado por inopia comprobada $y$, por ello, no podía la Administración negarse a prorrogarle su nombramiento interino y, en su substitución,. designar a otra servidora también en forma interina. Por lo demás, dado que se trata de una plaza vacante, debe la Administración, a la brevedad posible, sacarla a concurso, a fin de nombrar en ella a la oferente más calificada tal y como es su deber; pero en tanto ello no suceda, no puede separar del puesto al recurrente, no prorrogándole su nombramiento, $y$ designar a otra servidora interina por tener mejor calificación. En consecuencia, como lo actuado es arbitrario e ilegítimo, el recurso resulta procedente y así debe declararse" (Resolución No. 1682-96 de las 10:36 horas del 12 de abril de 1996 de la Sala Constitucional).

Finalmente, el Tribunal Constitucional ha llegado a analizar lo siguiente:

"...en nada varía el hecho de que una funcionaria interina se sustituye por otra interina, aspecto vedado por el criterio de esta Sala, agregando que en el presente caso no se atendió el interés de continuar con el nombramiento de la recurrente, porque "en su lugar se nombró a otra persona que el Servicio Civil envió como aferente la cual tiene mayor calificación..." . O, como también se informa en el sentido de que lo impugnado por la recurrente es cierto, pero que "se nombró a una funcionaria con mayor calificación, es decir con un grupo profesional superior al de la aqui recurrente, la oferente calificada por el Servicio Civil". (f. 6). La mayor calificación, o el grupo profesional superior, serian criterios categóricos si la administración cumpliera con el mandato constitucional (artículos 191 y 192) de integrar la planta docente mediante concurso, pues con este procedimiento hay garantía para quien legítimamente aspira al cargo de que ob- jetivamente se le valore y para la administración de atraer a los mejores para el servicio. Se daría asi trato de igualdad a los aspirantes, en cuanto a oportunidades, a través del camino de la publicidad, de la amplia competencia por la plaza y, consecuentemente de poder medir con precisión y amplitud su idoneidad (títulos, experiencia, publicaciones, idiomas, etc.). Sin embargo, la amplia praxis de esta Sala ha demostrado que el Ministerio de Educación, con la complacencia del Servicio Civil, se ha eximido de tales procedimientos y se ha limitado -en la mayoría de los casos- a nombrar interinos. Debemos tener como cierto que la recurrente es interina desde 1986, pues se trata de un hecho no rechazado por la autoridad recurrida, la que se limita a señalar, sin mayor esfuerzo, "no me consta". Es absolutamente increíble que hasta el primer semestre de 1996, es decir 10 años después de su ingreso, aparezca ofreciendo sus servicios, en lista de elegibles del Servicio Civil, una persona calificada como VT6 y a la que precisamente se le ubicó en la plaza que por diez años había desempeñado aquélla. El caso evidencia un manejo inadecuado, por el cual la propia administración ha tejido una cadena de nombramientos, antitécnica $y$ hasta contraria a los intereses públicos si se quiere; pero que no puede llegar a despejar sino a través y con utilización de los mecanismos apropiados. Y no puede la Sala resolver de otra manera, ya que mantiene la tesis de que el interino ha adquirido un derecho a la estabilidad, que solamente cede ante el funcionario que ostente la plaza en propiedad, sea que la recobre (al cesar sus vacaciones, el permiso, la incapacidad, etc.), o para la cual haya sido nombrado a través de un concurso legalmente celebrado. Toda otra argumentación carece de fuerza contra la estabilidad del interino. No está de más indicar que un correcto manejo de personal y el mejor cumplimiento de los objetivos y filosofía en que se basa el régimen de servicio civil, particularmente cuando se trata de personal profesional como al que hacemos referencia en esta sentencia, debe partir de un cambio en la actitud tradicionalmente mantenida por la administración pública. Por lo expuesto, procede declarar con lugar el recurso" (Resolución No. 2124-96 de las 15:09 horas del 8 de mayo de 1996).

\section{Conclusión}

En términos generales los servidores interinos de la Administración Pública cuentan con una estabilidad relativa que la Sala Constitucional les ha venido reconociendo y la propia Administración Pública en forma creciente ha venido respetando, de modo que el derecho fundamental constitucionalmente reconocicto al trabajo impide que un servidor interino o sea sustituído por otro en igual condición de temporalidad de su nombramiento. 
En el colectivo docente, dicha regla tiene plena aplicación, aún y cuando por la naturaleza del servicio público educativo y las normas que lo informan en materia estatutaria, el Tribunal Constitucional ha sostenido reiteradamente que las designaciones interinas de maestros y profesores por inopia, sea de aspirantes, es decir con sólo estudios secundarios concluidos, o de autorizados, que son los que poseen estudios superiores pero en áreas ajenas a la Educación y por lo mismo sin formación pedagógica, pueden en ambos casos ser sustituídos en el siguiente curso lectivo por otros servidores que, aunque igualmente designados en forma interina, tengan a su haber estudios universitarios en educación que per se les permite ser considerados como docentes titulados y por lo mismo con mejor derecho, en el tanto deja de existir la inopia que en el caso concreto justificó esos nombramientos anteriormente, aparte de que de esa forma se asegura mayor excelencia en el servicio público educativo que se presta.

La experiencia cotidiana que año con año se vive en esta materia, da cuenta de que persiste en algunos casos la violación grosera de los derechos de los servidores interinos docentes que son sustituidos arbitrariamente por otro interino por la Administración, afectados a quienes no les queda mas que acudir a la vía de amparo para demandar el que les sea restablecido su derecho.

No obstante, es también preocupante el persistente abuso que año con año se viene presentando de parte de servidores que habían sido nombrados por inopia y que son sustituidos por personal calificado -aunque repetimos también interinamente-, en cuyo caso plantean un amparo logrando con ello su restitución y el cese del docente calificado mientras la Sala Constitucional resuelve, hecho que se producirá meses después.

En tal caso, evidentemente el perjuicio es grave tanto para el educador como para el propio proceso educativo.

Por un lado para el servidor calificado, que se ve privado de su nombramiento en virtud de la suspensión de pleno derecho que opera con la interposición del amparo, afectando su derecho al trabajo y a su salario, mientras se declara sin lugar el recurso y vuelve a ser nombrado, aunque ya para entonces habrá perdido tres, cuatro o cinco meses de labor y remuneración respectiva, situación que repercutirá laboralmente en distintos aspectos: perderá en su totalidad el derecho al incentivo del mes de setiembre por ampliación al curso lectivo al no haber laborado más de un mes, su aguinaldo y salario escolar será mucho menor, contará con menos antigüedad para efectos de aumentos anuales y pensión, etc. para no hablar de otros perjuicios personales.

Por otro lado, el proceso educativo es el más afectado, piénsese en niños de primer o segundo grado que inician el curso lectivo con una maestra, a los pocos días les ponen a otra y a los meses les vuelven a poner a la primera, o bien si se tratara de sextos grados o undécimos años que presentan las pruebas nacionales, dado que esos cambios originan graves perturbaciones al normal desarrollo de las lecciones y el proceso de enseñanzaaprendizaje.

A corto plazo, la solución práctica y justa consistiría en que el Tribunal Constitucional, de previo a dar curso al amparo, brinde una audiencia por 24 horas al Ministerio de Educación Pública para que informe acerca de si se trata o no en la especie de la sustitución de un interino por otro, y de ser cierto, que se indique en ambos casos qué calificación profesional tienen acreditada los dos servidores.

De esa forma, de manera ágil y con la celeridad requerida se podría atender el fondo de estas reclamaciones, para que el recurso esté resuelto ojalá dentro del mes siguiente a la interposición del amparo, y la justicia sea así pronta y cumplida.

Esperamos que el presente amplio repaso por esta materia, permita un mejor conocimiento del estado actual de la misma, a efectos de que se pueda contar en el quehacer diario con una mayor seguridad jurídica $y$ 
un respeto tanto del marco legal vigente como de los derechos fundamentales de los educadores.

Finalmente, confiamos en que también de esta manera los propios educadores eviten abusar de la vía de amparo con el único propósito de conseguir "prórrogar artificialmente sus nombramientos mientras se resuelve el amparo" en supuestos que, como aquí se han estudiado, son totalmente improcedentes, perjudicando no sólo el mejor derecho de sus colegas, sino la normal marcha del curso lectivo y el derecho a la educación de los niños y jóvenes en las aulas.

\section{Notas}

1. Conferencia impartida a los 20 Directores Regionales del Ministerio de Educación Pública con motivo de su reunión mensual celebrada en La Fortuna de San Carlos, el 24 de junio del año 1999.

2. Jefe a.i. de la Oficina Jurídica de la UNED.

3. Para conocer la evolución y alcances en términos más generales de los derechos de los agentes públicos interinos puede verse el dictamen AJ-52999 del 30 de setiembre de 1999 de la Dirección General de Servicio Civil.

4. Se habla en estos casos de interino sustituto, reemplazante, subrogante o suplente, que es aquel que hace las veces de otro que se encuentra ausente o impedido de ejercer un empleo o función de la cual es titular, suplencia que se diferencia del interino en plaza vacante, es decir, del que se encuentra nombrado interinamente en un puesto o empleo público que carece de titular.

5. Para un estudio mayor de los derechos a favor de los servidores interinos en la jurisprudencia constitucional, puede verse el oficio AJ-529-99 de fecha 29 setiembre de 1999, emanado de la Asesoría Jurídica de la Dirección General de Servicio Civil.

6. Sobre el derecho al trabajo como derecho fundamental pueden verse las resoluciones Nos. 2631$95,3467-93,5023-93,1775-94,1230-94$ y $022-95$, entre otras.

7. Para profundizar en la evolución genérica de este tema ver el artículo "Los Derechos de Estabilidad y trabajo en el empleo público", del Lic. Celín Arce Gómez, publicado en la Revista Judicial No. 69 de setiembre de 1998, pgs. 31-47.
8. En tal sentido pueden consultarse las resoluciones de la Sala Constitucional Nos. 2115-91 de 9:50 hrs. del 18 de octubre de 1991 y las números 1349-94, 6671-94, 7145-94 y 2887-99 de las 17:21 horas del 21 de abril de 1999, entre muchas otras, que la distingue de la estabilidad propia, pero siempre como derecho al empleo.

9. Véase la resolución de la Sala Constitucional No. 2041-95 de las 16:12 horas del 24 de abril de 1995 , que habla de la sustitución de un destacado vuelto a reubicar -aún sin ocupar la plaza respectiva- pero que fue sustituido por un interino.

10. Véase la resolución de la Sala Constitucional No. 1989-92 de las 16:42 horas del 23 de julio de 1992.

11. Véase la resolución de la Sala Constitucional No. 226-93 de las 12:33 horas del 15 de enero de 1993.

12. Véase la resolución de la Sala Segunda de la Corte Suprema de Justicia de las 8:40 horas del 10 de noviembre de 1995.

13. Véase la resolución No.2686-93 de las 10:18 horas del 11 de junio de 1993.

14. Véase la resolución de la Sala Constitucional No. 7145-94 de las 16:21 horas del 02 de diciembre de 1993 .

15. Véase las resoluciones de la Sala Constitucional Nos. 4744-93 de las 16:21 horas del 29 de setiembre de 1993 y $6773-93$ de las 16:30 horas del 22 de diciembre de 1993. Sin embargo, tal posibilidad de cesar a un interino que no llena los requisitos de un puesto no debe hacerse arbitrariamente, sea sin darle audiencia previa y el derecho de defensa -véase la resolución de la Sala Constitucional No. 6089-98 de las 15:12 horas del 26 de agosto de 1998-.

16. Véase la resolución No. 2940-95 de las $17: 42$ horas del 07 de junio de 1995 de la Sala Constitucional.

17. Véase la resolución de la Sala Constitucional No. 8845-99 de las 15:00 horas del 12 de noviembre de 1999.

18 Véase las resoluciones de la Sala Constitucional Nos. 4946-95 de las 16:36 horas del 06 de setiembre de $1995,223-98$ de las 16:48 horas del 14 de enero de 1998 y $5522-99$ de las 14:51 horas del 20 de julio de 1999.

19 Siempre que se llegue a concretar dicho escogimiento en propiedad, dado que si en definitiva 
no se presenta el escogido y se nombra a otro interino distinto al que venía anteriormente ocupando el puesto, cabe el amparo, conforme la resolución de la Sala Constitucional No. 7151-94 de las 16:39 horas del 02 de diciembre de 1994 .

20. Véase la resolución de la Sala Constitucional No. 5522-99 de las 14:51 horas del 20 de julio de 1999.

21. Véase las resoluciones de la Sala Constitucional No. 7249-94 y 1943-99.

22. Véase la resolución de la Sala Constitucional No. 3851-94 de las 9:09 horas del 29 de julio de 1994.

23. Véase la resolución No. 1763-98 de las 17:40 horas del 11 de marzo de 1998 de la Sala Constitucional.

24. Véasen las resoluciones de la Sala Constitucional Nos. 4017-95, 3672-97, 3966-97, 1468-98 y 1815 99. Incluso si hay en un centro educativo dos interinas y por matrícula solo un código se necesita, se cesa a la que posee el menor grupo, conforme resolución 1653-92 de las 9:39 horas del 19 de junio de 1992

25. Véase las resoluciones de la Sala Constitucional Nos. 296-95 de las 11:54 horas del 13 de enero de $1905 \mathrm{v}$ 6012-99 de las 15:30 horas clel 03 de agosto de 1999.

26. Véase la resolución de la Sala Constitucional No. 4191-94 de las 12:51 horas del 12 de agosto de 1994.

27. Véase la resolución 2065-93 de las 15:48 horas del 14 de mayo de 1993 de la Sala Constitucional.

28. Decreto Ejecutivo.

29. Véase al respecto la resolución No. 6329-98 de las 18:12 horas de la Sala Constitucional.

30. Para desarrollar este apartado agradezco al Lic. Carlos Campos, Director de la Asesoría Jurídica del MEP, por facilitarme mucha de la jurisprudencia en materia de amparos que se analiza.

31. Definidos por el artículo 108 como los que poseen título docente, según las especialidades respectivas, es decir, quienes han cursado estudios formales para ser docentes.

32. Definidos por el artículo 109 como aquellos que tienen un título profesional pero no con estudios pedagógicos.
33. Definidos por el artículo 110 , y son quienes no tienén no preparación académica profesional ni especifica -docente- ni general -en otras profesiones-, constituido por lo general por personas que solamente han concluido la enseñanza secundaria.

34. Véase las resoluciones de la Sala Constitucional Nos. 6983-94 de las 15:51 horas del 29 de noviembre de 1994, 2528-95 de las 17:30 horas del 17 de mayo de $1995 ; 1198-96$ de las $16: 12$ horas del 13 de marzo de 1996, 3169-99 de las 10:51 horas del 30 de abril de 1999, 1923-99.

35. Véase la resolución de la Sala Constitucional 2887-99 de las 17:21 horas del 21 de abril de 1999. Sin embargo, en alguna ocasión el mismo Tribunal Constitucional se ha contradicho como por ejemplo en la resolución 5905-99 de las 16:12 horas del 28 de julio de 1999. Debe considerarse que tampoco cabe sustituir aún por un interino calificado a un autorizado que se encuentre amparado por los términos del numeral 129 de la Ley de Carrera Docente.

36. Incluso, si se había aplicado un ascenso interino por inopia, el mismo puede concluir posteriormente cuando se encuentre para nombrar interinamente en su sustitución un candidato que reúna todos los requisitos exigidos, conforme la resolución No. 2174-93 de las 15:30 horas del 03 de mayo de 1995 .

37. Véase a este respecto la resolución de la Sala Constitucional No. 4176-95 de las 10:51 horas del 28 de julio de 1995.

38. Véanse las resoluciones Nos. 1839-97 de las 10:21 horas del 04 de abril de 1997, 5111-98 de las 19:42 horas del 15 de julio de 1998.

39. Véase al respecto la resolución No. 926-93 de las 11:12 horas del dos de febrero de 1993 de la Sala Constitucional. No obstante, en el caso de que ambos sean aspirantes, uno con convenio con las universidades estatales y el que se sustituye no, a pesar de encontrarse en situaciones distintas al ser más idóneo el primero, la Sala en al menos un caso no aceptó la sustitución -resolución 2182-93 de las 14:37 horas del 21 de mayo de 1993-.

40. Existen numerosos fallos a este respecto, algunos de los casos se transcriben más adelante. Pueden verse adicionalmente los siguientes: 2805-95; 925-96 y $1572-96$. 